\title{
Analisis Faktor Penyebab Dismenorea Pada Siswi di Asrama Puteri Madrasah Aliyah Negeri Model 1 Manado
}

\author{
Gusti Ayu Tirtawati ${ }^{1}$, Martha Debora Korompis ${ }^{1}$, Juwita Rahayu Betrang ${ }^{1}$ \\ I, Jurusan Kebidanan Poltekkes Kemenkes Manado \\ Email : tirtagustiayu@gmail.com
}

\begin{abstract}
ABSTRAK
Latar Belakang: Dismenorea adalah keluhan yang sering dialami perempuan pada bagian perut bawah. Dismenorea dapat dibagi menjadi dua yaitu dismenorea primer dan sekunder. Dismenorea primer adalah nyeri haid yang dirasakan tanpa adanya kelainan pada alat reproduksi. Dismenorea sekunder adalah nyeri haid yang berhubungan dengan berbagai keadaan patologis di organ genitalia. Menurut data dari World Health Organization (WHO) didapatkan kejadian sebesar 1.769.425 jiwa $(90 \%)$ wanita yang mengalami dismenorea.

Tujuan: Penelitian ini bertujuan untuk mengetahui adanya hubungan antara usia menarke, status gizi, dan siklus haid dengan dismenorea pada siswi di Asrama Puteri Madrasah Aliyah Negeri Model 1 Manado.

Metode: Jenis penelitian yang digunakan metode penelitian yang bersifat deskriptif analitik dengan metode cross sectional yang dilakukan kepada 75 responden.

Hasil : Hasil penelitian, didapatkan 44 responden (59\%) yang usia menarke $\geq 12$ tahun mengalami dismenorea dengan nilai $p=0,084,36$ responden $(48 \%)$ yang status gizi normal mengalami dismenorea dengan nilai $p=0,019$, dan 57 responden $(76 \%)$ yang siklus haid normal mengalami dismenorea dengan nilai $p=0,022$.

Kesimpulan : Berdasarkan hasil penelitian, dapat disimpulkan bahwa usia menarke tidak ada hubungan dengan dismenorea, sedangkan status gizi dan siklus haid memiliki hubungan terhadap dismenorea pada siswi di Asrama Puteri Madrasah Aliyah Negeri Model 1 Manado karena nilai $p$ value $<$ a-value $(0,05)$.
\end{abstract}

Kata Kunci : Dismenorea; usiamenarke; status gizi, siklus haid

\section{PENDAHULUAN}

Masa remaja adalah masa peralihan dari pubertas kedewasa, yaitu pada umur 11 sampai 19 atau 20 tahun.Pada masa ini mulai terbentuk perasaan identitas individu, pencapaian emansipasi dalam keluarga, dan usahanya untuk mendapatkan kepercayaan diri dari ayah dan ibu (1). Menstruasi atau haid adalah perdarahan periodik pada uterus yang dimulai sekitar 14 hari setelah ovulasi (2)
Dismenorea adalah keluhan yang sering dialami perempuan pada bagian perut bawah.Dismenorea dapat dibagi menjadi dua yaitu dismenorea primer dan sekunder.Dismenorea primer adalah nyeri haid yang dirasakan tanpa adanya kelainan pada alat reproduksi, dengan kata lain ini adalah rasa nyeri yang biasa dirasakan oleh perempuan saat mengalami haid. 
Dismenorea sekunder adalah nyeri haid yang berhubungan dengan berbagai keadaan patologis di organ genitalia, misalnya endometriosis, adenomiosis, mioma uteri, stenosis serviks, penyakit radang panggul, perlekatan panggul, atau irritable bowel syndrome.

Menurut data dari World Health Organization (WHO) didapatkan kejadian sebesar 1.769.425 jiwa (90\%) wanita yang mengalami dismenorea. Menurut Novia dan Puspitasari dalam Ismail menjelaskan bahwa gizi yang berlebihan pun dapat menimbulkan dismenorea.Faktor penunjang yang dapat menimbulkan dismenorea juga yaitu kebiasaan mengkonsumsi makanan yang tidak sesuai, seperti mengkonsumsi junk food baik sebagai kudapan atau Mengkonsumsi makanan yang berlemak dapat meningkatkan hormon prostaglandin yang dapat menyebabkan nyeri dibagian perut bawah atau dismenorea (3) Hasil penelitian oleh Sophia menunjukkan ada hubungan yang bermakna antara status gizi dan usia menarke terhadap dismenorea ${ }^{(4)}$.

\section{METODE}

Penelitian ini dilakukan menggunakan metode penelitian yang bersifat deskriptif analitik dengan menggunakan metode cross sectional yang dilaksanakan di Asrama Puteri Madrasah Aliyah Negeri Model 1 Manado pada tahun 2017. Populasi penelitian ini adalah siswi kelas X dan XI di Asrama Puteri pada tahun ajaran 2016/2017 yang telah mendapat haid. Pengumpulan data yang digunakan pada penelitian ini adalah menggunakan data primer dan data sekunder. Data primer didapatkan melalui kuesioner yang dibagikan dan diisi responden sedangkan data sekunder diperoleh melalui bagian kurikulm dan ibu asrama puteri di Madrasah Aliyah Negeri Model 1 Manado.

Data yang telah dikumpulkan diolah dan dianalisis dengan menggunkan program SPSS 20 melalui cleaning, coding, scoring, dan entering. Analisis data disajikan dalam bentuk tabel dan narasi.

\section{HASIL}

1. Analisis Univariate 
Tabel 1 Distribusi responden berdasarkan umur di Asrama Puteri Madrasah Aliyah Negeri Model 1 Manado tahun 2017

\begin{tabular}{lcc}
\hline Karakteristik Responden & \multicolumn{2}{c}{ Jumlah } \\
\cline { 2 - 3 } & $\mathrm{f}$ & \\
\hline Usia & & \\
13 Tahun & - & \\
14 Tahun & - & $29,33 \%$ \\
15 Tahun & 22 & $53,33 \%$ \\
16 Tahun & 40 & $17,33 \%$ \\
17 Tahun & 13 & \\
18 Tahun & - & \\
19 Tahun & - & $33 \%$ \\
Usia Menarche & & $67 \%$ \\
$<12$ Tahun & 25 & $64 \%$ \\
$\quad$ 12 Tahun & 50 & $36 \%$ \\
Satatus Gizi & 48 & \\
$\quad$ Normal & 27 & 12 \\
$\quad$ Tidak Normal & & \\
Siklus Haid & 66 & \\
$\quad$ Normal & 9 & \\
$\quad$ Tidak Normal & & \\
\hline
\end{tabular}

Hasil analisis data tabel 1 gizi terbanyak adalah normal sebanyak 48 menunjukkan bahwa distribusi umur responden (64\%).Dari 75 responden terbanyak dari usia 13 hingga 19 tahun (100\%) dan siklus haid terbanyak adalah terdapat pada umur 16 tahun yang normal sebanyak 66 responden (88\%).Dari berjmlah 40 respoden (53,33\%), usia 75 responden (100\%) di Asrama Puteri menarke terbanyak adalah $\geq 12$ tahun Madrasah Aliyah Negeri Model 1 Manado. dengan jumlah 50 responden $(67 \%)$, status

2. Analisis bivariat 
Tabel 2. Hubungan antara usia menarke dengan dismenorea di Asrama Puteri Madrasah Aliyah Negeri Model 1 Manado tahun 2017

\begin{tabular}{|c|c|c|c|c|c|c|c|}
\hline \multirow{3}{*}{ Usia menarke } & \multicolumn{6}{|c|}{ Disminorea } & \multirow{3}{*}{$p$} \\
\hline & \multicolumn{2}{|c|}{ Ada } & \multicolumn{2}{|c|}{ Tidak } & \multicolumn{2}{|c|}{ Total } & \\
\hline & $\mathbf{N}$ & $\%$ & $\mathbf{N}$ & $\%$ & $\mathbf{N}$ & $\%$ & \\
\hline \multicolumn{8}{|l|}{ Usia Menarche } \\
\hline$<12$ Tahun & 18 & 24 & 7 & 9 & 25 & 33 & 0,084 \\
\hline$\geq 12$ tahun & 44 & 59 & 6 & 8 & 50 & 67 & \\
\hline \multicolumn{8}{|l|}{ Status Gizi } \\
\hline Normal & 36 & 48 & 12 & 16 & 48 & 64 & 0,019 \\
\hline Tidak Normal & 26 & 35 & 1 & 1 & 27 & 36 & \\
\hline \multicolumn{8}{|l|}{ Siklus Haid } \\
\hline Normal & 57 & 76 & 9 & 12 & 66 & 88 & 0,022 \\
\hline Tidak Normal & 5 & 7 & 4 & 5 & 9 & 12 & \\
\hline
\end{tabular}

Berdasarkan tabel 2 menunjukkan bahwa yang mengalami dismenorea terbanyak terdapat pada usia menarke $>12$ tahun dengan jumlah 32 responden (43\%) dengan $p=0,084$. Responden yang mengalami dismenorea terbanyak terdapat pada status gizi normal dengan jumlah 36 responden $(48 \%)$ dengan $p=0,019$. Status gizi normal dengan jumlah 57 responden (76\%) dengan $p=0,022$.

\section{PEMBAHASAN}

Hasil penelitian yang dilakukan oleh peneliti menunjukkan bahwa dismenorea lebih banyak didapatkan pada usia menarke $\geq 12$ tahun dengan jumlah 44 responden (59\%) sedangkan pada usia menarke yang $<12$ tahun didapatkan 18 responden (24\%) yang mengalami square didapatkan nilai $p=0,084$ yang

berarti tidak ada hubungan yang bermakna antara usia menarke dengan dismenorea.

Hasil penelitian yang dilakukan oleh Wahyu Fitriana pada 58 responden didapatkan hasil ada hubungan antara usia menarke dengan dismenorea dengan menggunakan uji chi square diperoleh nilai $p=0,047^{(5)}$.

Berdasarkan hasil penelitian yang dilakukan oleh peneliti menunjukkan bahwa dismenorea lebih banyak didapatkan pada status gizi normal dengan jumlah 36 responden (48\%) sedangkan tidak normal berjumlah 26 responden (35\%). Setelah dilakukan uji chi square didapatkan hasil bahwa ada hubungan 
antara status gizi dengan dismenorea. Hal ini dapat dilihat pada tabel 10 , dengan nilai $p=0,019$.

Menurut Sudjana dalam Fitriana menyatakan semakin banyak lemak semakin banyak pula prostaglandin yang dibentuk, sedangkan peningkatan kadar prostaglandin dalam sirkulasi darah diduga sebagai penyebab nyeri haid. Prostaglandin menyebabkan peningkatan aktivitas uterus dan serabut-serabut syaraf terminal rangsangan nyeri.Jika prostaglandin dilepaskan dalam jumlah berlebih ke dalam peredaran darah, maka selain nyeri haid timbul pula diare, mual dan muntah ${ }^{(\mathbf{5})}$.

Berdasarkan hasil penelitian yang dilakukan oleh peneliti menunjukkan bahwa dismenorea lebih banyak didapatkan pada siklus haid normal dengan jumlah 57 responden (76\%) sedangkan siklus haid tidak normal terdapat pada 5 responden $(7 \%)$. Setelah dilakukan uji chi square didapatkan nilai $p=0,022$ yang berarti ada hubungan antara siklus haid dengan dismenorea. Hasil penelitian yang dilakukan oleh Andi Nurul Rifqah Utami, dkk menunjukkan bahwa tidak ada hubungan antara siklus haid dengan dismenorea. didapatkan nilai $p=0,068^{(6)}$.

\section{KESIMPULAN}

Tidak ada hubungan antara usia menarke dengan dismenorea pada siswi di Asrama Puteri Madrasah Aliyah Negeri Model 1 Manado, Ada hubungan antara status gizi, siklus haid dengan dismenorea pada siswi di Asrama Puteri Madrasah Aliyah Negeri Model 1 Manado,

\section{SARAN}

Hasil penelitian ini diharapkan dapat menambah peningkatan mutu pelayanan khususnya kesehatan reproduksi pada remaja puteri di Madrasah Aliyah Negeri Model 1 Manado.

\section{DAFTAR PUSTAKA}

1. Prawirohardjo S. Ilmu Kandungan. Jakarta: PT Bina Pustaka Sarwono Prawirohardjo; (2011).

2. Bobak I, Lowdermilk, Jensen. Buku Ajar Keperawatan Maternitas. Jakarta: EGC; (2012).

3. Ismail I, Kundre R, Lolong J. Hubungan Tingkat Stres dengan Kejadian Dismenorea pada Mahasiswi Semester VIII Program Studi Ilmu Keperawatan Fakultas Kedokteran Universitas Sam Ratulangi Manado. J Keperawatan. (2015)

4. Sophia F, Sori M, Jemadi. Faktor - Faktor yang Berhubungan dengan Dismenore pada Siswi SMK Negeri 10 Medan. Univ Sumatera Utara. (2013)

5. Fitriana W. Faktor-Faktor yang Mempengaruhi Dismenore pada Mahasiswi di Akademi Kebidanan Meuligo Meulaboh Tahun 2013. (2013)

6. Utami ANR, Ansar J SD. Faktor yang Berhubungan dengan Kejadian Dismenorea pada Remaja Putri di SMAN 1 Kahu District In Bone. (2013) 